\title{
PENGARUH BRAND IMAGE, PRODUCT INVOLVEMENT, DAN BRAND ENGAGEMENT TERHADAP PURCHASE INTENTION TEH PUCUK DI KOTA JAKARTA
}

\author{
Annisa Intan Ramadhan \\ Program Studi Magister Manajemen Universitas Tarumanagara \\ annisa.dck@gmail.com \\ Chairy \\ Program Studi Magister Manajemen Universitas Tarumanagara
}

\begin{abstract}
This research aims to find out influence of Brand Image, Product Involvement, and Brand Engagement to Teh Pucuk's Purchase Intention in Jakarta. Research conducted by distributing questionnaires to 272 respondents randomly. Analysis technique used is technique of quantitative analysis. Data of this research was taken from August until Dec 2018. The research data was analyzed by SmartPLS application. The results showed that Brand Image, Product Involvement, and Brand Engagement had significantly influence on Teh Pucuk's Purchase Intention. The population in this study were people living in Jakarta, researchers took samples of 272 respondents using the questionnaire method. The sampling technique used is simple random sampling, where each element of the population has the same opportunity to be selected as a sample. Brand Engagement had influence Purchase Intention; Brand Image had influence Brand Engagement; Brand Image had influence Purchase Intention; Product Involvement had influence Brand Engagement; and Product Involvement had influence Purchase Intention. Also this research had indirect effect, that Brand Engagement had influence as mediator between Brand Image and Purchase Intention and Product Involvement and Purchase Intention.
\end{abstract}

Abstrak : Penelitian ini bertujuan untuk mengetahui pengaruh Brand Image, Product Involvement, dan Brand Engagement terhadap Purchase Intention Teh Pucuk di Jakarta. Penelitian dilakukan dengan membagikan kuesioner kepada 272 responden secara acak. Teknik analisis yang digunakan adalah teknik analisis kuantitatif. Data penelitian ini diambil dari Agustus hingga Desember 2018. Data penelitian dianalisis dengan aplikasi SmartPLS. Hasil penelitian menunjukkan bahwa Brand Image, Product Involvement, dan Brand Engagement memiliki pengaruh yang signifikan terhadap Purchase Intention Teh Pucuk. Populasi dalam penelitian ini adalah masyarakat yang tinggal di Jakarta, peneliti mengambil sample sebanyak 272 responden dengan menggunakan metode kuesioner. Teknik sampling yang digunakan adalah simple random sampling atau sample acak sederhana dimana setiap elemen populasi mempunyai kesempatan yang sama untuk dipilih menjadi sample. Brand Engagement memengaruhi Purchase Intention; Brand Image memengaruhi Brand Engagement; Brand Image memengaruhi Purchase Intention; Product Involvement mempengaruhi Brand Engagement; dan Product Involvement memengaruhi Purchase Intention. Penelitian ini juga memiliki pengaruh tidak langsung, bahwa Brand Engagement berpengaruh sebagai mediator antara Brand Image dengan Purchase Intention, dan Product Involvement dengan Purchase Intention.

Keywords : Brand Image, Product Involvement, Brand Engagement, Purchase Intention 


\section{PENDAHULUAN}

Teh adalah jenis minuman yang paling banyak dikonsumsi setelah air (Damayanthi, 2008). Kebiasaan minum teh tidak hanya dikenal di Indonesia, tetapi juga hampir di seluruh dunia. Pada zaman yang semakin modern saat ini tradisi minum teh sangat jarang dilakukan oleh masyarakat Indonesia, karena keterbatasan waktu untuk menyajikan teh tradisional, ditinjau dari padatnya aktifitas masyarakat Indonesia pada umumnya yaitu sibuk dengan pekerjaan masing-masing sehingga masyarakat membutuhkan segala sesuatu yang praktis dan siap saji tanpa merugikan waktu lama serta tenaga yang lebih. (Ajisaka, 2012).

Pasar minuman ringan di Indonesia saat ini didominasi oleh air minum dalam kemasan (AMDK) atau RTD Water yang memiliki market share $84 \%$ dari total pasar minuman ringan siap saji dalam kemasan. Sedangkan minuman ringan berkarbonasi cenderung stagnan, baik karena banyaknya pilihan minuman lainnya, maupun karena ditimpa rumor masalah kesehatan. (market share 3,6\%). (Asosiasi Industri Minuman Ringan).

Bisa dikatakan Teh Pucuk merupakan pemain baru bila dibandingkan dengan kompetitornya yaitu Teh Botol Sosro, akan tetapi berdasarkan data berikut Teh Pucuk Harum terus meningkatkan performanya dengan dibuktikan adanya peningkatan peringkat top brand award dari tahun 2017 ke 2018.

\begin{tabular}{|l|l|l|}
\hline $\begin{array}{l}\text { TEH DALAM KEMASAN SIAP } \\
\text { MINUM }\end{array}$ & TBI & TOP \\
\hline MEREK & $32.0 \%$ & TOP \\
\hline Teh Botol Sosro & $32.7 \%$ & TOP \\
\hline Teh Pucuk Harum & $22.7 \%$ & TOP \\
\hline Teh Gelas & $12.6 \%$ & \\
\hline Ultra Teh Kotak & $6.8 \%$ & \\
\hline Frestea & $6.3 \%$ & \\
\hline
\end{tabular}

Tabel 1.1 Top Brand Fase 12017 Kategori : Makanan dan Minuman

Sumber:http://www.topbrand-award.com/top-brand-survey/surveyresult/top_brand_index_2017_fase_1 (Diakses tanggal 23/05/18 22:47)

Berdasarkan Tabel 1.1 di atas, TOP three kategori teh dalam kemasan siap minum pada fase I tahun 2017 dikuasai oleh Teh Botol Sosro dengan TBI 32,0\%; urutan kedua ditempati oleh Teh Pucuk Harum dengan TBI 22,7\%; dan di urutan ke tiga ditempati oleh Teh Gelas dengan TBI 12,6\%.

\begin{tabular}{l|l|l|}
$\begin{array}{l}\text { TEH DALAM KEMASAN SIAP } \\
\text { MINUM }\end{array}$ \\
\hline MEREK & TBI & TOP \\
\hline Teh Pucuk Harum & $32.3 \%$ & TOP \\
\hline Teh Botol Sosro & $26.8 \%$ & TOP \\
\hline Teh Gelas & $9.6 \%$ & \\
\hline Frestea & $9.2 \%$ & \\
\hline Ultra Teh Kotak & $4.1 \%$ & \\
\hline
\end{tabular}

Tabel 1.2. Top Brand Fase 12018 Kategori : Makanan dan Minuman (23/05/18 22:49)

Sumber:http://www.topbrand-award.com/top-brand-survey/surveyresult/top_brand_index_2018_fase_1

Berdasarkan Tabel 1.2 di atas, TOP three kategori teh dalam kemasan siap minum pada fase I tahun 2018 dikuasai oleh Teh Pucuk Harum dengan TBI 32,3\%; Teh Botol Sosro 26,8\%; dan Teh Gelas dengan TBI 9,6\%. Terlihat bahwa Teh Pucuk Harum mampu menggeser posisi Teh Botol Sosro di urutan pertama jika dibandingkan dengan tahun sebelumnya. 


\section{TINJAUAN PUSTAKA}

Mengenai arti engagement, Jayswal \& Vora (2017) menjelaskan bahwa Engagement adalah tentang menghubungkan konsumen dan brand dengan cara yang memungkinkan pengalaman dua arah. Engagement menyiratkan tingkat berbasis relasional yang lebih dalam dan dengan demikian, memiliki tempat penting dalam berkontribusi terhadap pemahaman hasil pelanggan, yaitu hasil yang berhubungan dengan loyalitas (Bowden, 2009). Patterson (2006), tingkat engagement dapat bervariasi berdasarkan faktor termasuk industri dan atribut produk / layanan.

Brand Image sangat diperlukan untuk pemasaran di mana pelanggan menyimpulkan kualitas produk dengan citra merek dan selanjutnya membangkitkan perilaku pembelian (Chien-Hsiung, 2011). Brand Image membentuk dasar untuk membuat keputusan pemasaran strategis yang lebih baik tentang penargetan segmen pasar tertentu dan penentuan posisi suatu produk (Lee, James, dan Kim, 2014).

Product involvement secara umum didefinisikan sebagai persepsi konsumen mengenai tingkat hubungan personal dari suatu produk bagi dirinya (Quester \& Lim, 2003). Radder dan Huang (2008) menemukan bahwa tingkat awareness untuk high involvement product jauh lebih besar bila dibandingkan dengan low involvement product. Product involvement juga didefinisikan sebagai tingkat di mana konsumen merasakan produk menjadi penting (Loureiro dan Ribeiro, 2013). Product involvement secara umum didefinisikan sebagai persepsi konsumen terhadap kepentingan dari suatu kategori produk yang didasarkan pada kebutuhan, nilai, serta minat konsumen (Bian and Moutinho, 2011). Olson (2001) product involvement sebagai tingkat perhatian dan ketertarikan konsumen terhadap suatu produk sehingga menimbulkan kesiapan atau keinginan untuk membeli

Assael (2001) purchase intention merupakan perilaku yang muncul dari calon konsumen atau konsumen sebagai sebuah respon terhadap suatu barang. Purchase intention ditentukan oleh manfaat dan nilai yang dirasakan oleh konsumen (Wang dan Tsai, 2014). Purchase intention juga dapat diartikan sebagai konsumen lebih memilih untuk membeli produk atau layanan karena merasa bahwa membutuhkan produk atau jasa tersebut (Madahi dan Sukati, 2012). Jaafar dan Laalp (2013) menjelaskan bahwa purchase intention adalah penggunaan alat yang efektif dalam memprediksi proses pembelian. Shah (2012), purchase intention ditentukan juga oleh sikap konsumen terhadap merek dari barang yang hendak dibeli (atittude towards brands).

\section{METODOLOGI PENELITIAN DAN HIPOTESIS}

Populasi dalam penelitian ini mengambil sample sebanyak minimal 272 responden dengan menggunakan metode kuesioner. Teknik sampling yang digunakan adalah simple random sampling atau sample acak sederhana dimana setiap elemen populasi mempunyai kesempatan yang sama untuk dipilih menjadi sample. Penelitian ini dilakukan mulai bulan September 2018 sampai dengan bulan Desember 2018. Untuk mendapatkan data yang diperlukan, penulis mengadakan penelitian di Jakarta.

Berikut adalah konseptual modelnya

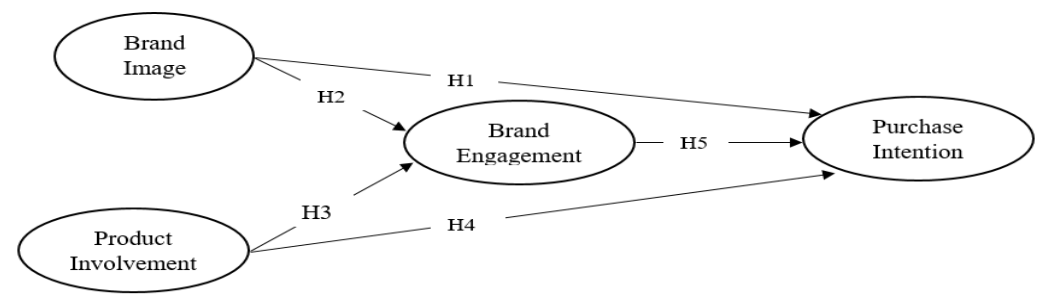

Dari model kerangka berpikir di atas, maka dapat disusun hipotesis sebagai berikut :

1) H1 : Terdapat pengaruh signifikan Brand Image terhadap Purchase Intention.

2) H2 : Terdapat pengaruh signifikan Brand Image terhadap Brand Engagement. 
3) H3 : Terdapat pengaruh signifikan Product Involvement terhadap Brand Engagement.

4) H4 : Terdapat pengaruh signifikan Product Involvement terhadap Purchase Intention.

5) H5 : Terdapat pengaruh signifikan Brand Engagement terhadap Purchase Intention.

6) H6 : Terdapat pengaruh signifikan Brand Image terhadap Purchase Intention yang dimediasi oleh Brand Engagement.

7) H7 : Terdapat pengaruh Product Involvement terhadap Purchase Intention yang dimediasi oleh Brand Engagement.

\section{HASIL DAN PEMBAHASAN}

Tabel 1.3

Hasil Uji Signifikansi

\begin{tabular}{|l|r|r|r|r|r|}
\hline & \multicolumn{1}{|c|}{$\begin{array}{c}\text { Original } \\
\text { Sample } \\
(\mathbf{O})\end{array}$} & $\begin{array}{c}\text { Sample } \\
\text { Mean } \\
(\mathbf{M})\end{array}$ & $\begin{array}{l}\text { Standard } \\
\text { Deviation } \\
\text { (STDEV) }\end{array}$ & $\begin{array}{c}\text { T Statistics } \\
(\mid \mathbf{O} / \text { STDE } \\
\text { V|) }\end{array}$ & $\begin{array}{c}\text { P } \\
\text { Values }\end{array}$ \\
\hline $\begin{array}{l}\text { BRAND ENGAGEMENT -> } \\
\text { PURCHASE INTENTION }\end{array}$ & 0.246 & 0.238 & 0.079 & 3.095 & $\mathbf{0 . 0 0 2}$ \\
\hline $\begin{array}{l}\text { BRAND IMAGE -> BRAND } \\
\text { ENGAGEMENT }\end{array}$ & 0.101 & 0.100 & 0.042 & 2.414 & $\mathbf{0 . 0 1 6}$ \\
\hline $\begin{array}{l}\text { BRAND IMAGE -> PURCHASE } \\
\text { INTENTION }\end{array}$ & 0.298 & 0.303 & 0.055 & 5.378 & $\mathbf{0 . 0 0 0}$ \\
\hline $\begin{array}{l}\text { PRODUCT INVOLVEMENT -> } \\
\text { BRAND ENGAGEMENT }\end{array}$ & 0.712 & 0.717 & 0.036 & 20.061 & $\mathbf{0 . 0 0 0}$ \\
\hline $\begin{array}{l}\text { PRODUCT INVOLVEMENT -> } \\
\text { PURCHASE INTENTION }\end{array}$ & 0.223 & 0.230 & 0.079 & 2.810 & $\mathbf{0 . 0 0 5}$ \\
\hline
\end{tabular}

a) H1 : Terdapat pengaruh signifikan Brand Image terhadap Purchase Intention.

Brand Image mempengaruhi Purchase Intention dengan nilai t statistik hitung $>\mathrm{t}$ tabel 1,96 (5,378 > 1,96). Dengan kata lain perusahaan yang memiliki produk atau citra perusahaan yang baik dapat mempengaruhi niat pembelian produk Teh Pucuk Harum.

b) $\mathrm{H2}$ : Terdapat pengaruh signifikan Brand Image terhadap Brand Engagement.

Brand Image mempengaruhi Brand Engagement dengan nilai t statistik hitung > t tabel 1,96 $(2,414>1,96)$. Dengan kata lain pelanggan yang memiliki perspektif positif terhadap merek Teh Pucuk Harum dapat mempengaruhi tingkat kegembiraan dan ketertarikan pelanggan, tingkat perhatian pelanggan terhadap Teh Pucuk Harum, keadaan menyenangkan pelanggan mencurahkan pikirannya pada Teh Pucuk Harum hingga tidak menyadari berlalunya waktu, dan tingkat rasa kesatuan pelanggan terhadap Teh Pucuk Harum.

c) H3 : Terdapat pengaruh signifikan Product Involvement terhadap Brand Engagement.

Product Involvement mempengaruhi Brand Engagement dengan nilai t statistik hitung > t tabel 1,96 (20,061 > 1,96). Dengan kata lain tingkat perhatian dan ketertarikan pelanggan terhadap Teh Pucuk Harum dapat mempengaruhi tingkat kegembiraan dan ketertarikan pelanggan, tingkat perhatian pelanggan terhadap Teh Pucuk Harum, keadaan menyenangkan pelanggan mencurahkan pikirannya pada Teh Pucuk Harum hingga tidak menyadari berlalunya waktu, dan tingkat rasa kesatuan pelanggan terhadap Teh Pucuk Harum.

d) H4 : Terdapat pengaruh signifikan Product Involvement terhadap Purchase Intention.

Product Involvement mempengaruhi Purchase Intention dengan nilai t statistik hitung > t tabel 1,96 $(2,810>1,96)$. Dengan kata lain komitmen pelanggan pada subjek pemikiran, perasaan, sikap dan respon perilaku terhadap Teh Pucuk Harum dapat mempengaruhi niat pelanggan untuk membeli Teh Pucuk Harum. Oleh karena itu 
pemasar harus mampu membangun motivasi pelanggan untuk membangun perilaku pembelian yang kuat melalui penyampaian informasi atau experience yang tepat.

e) H5 : Terdapat pengaruh signifikan Brand Engagement terhadap Purchase Intention.

Brand Engagement mempengaruhi Purchase Intention dengan nilai t statistik hitung > t tabel 1,96 (3,095>1,96). Dengan kata lain tingkat kegembiraan dan ketertarikan pelanggan dapat mempengaruhi niat pelanggan untuk membeli Teh Pucuk Harum.

f) H6 : Terdapat pengaruh signifikan Brand Image terhadap Purchase Intention yang dimediasi oleh Brand Engagement.

Brand Engagement memiliki pengaruh sebagai mediator Brand Image terhadap Purchase Intention dengan nilai t statistik hitung $>\mathrm{t}$ tabel 1,96 $(1,977>1,96)$. Dengan kata lain indikator - indikator Brand Engagament yang digunakan dalam penelitian ini berperan sebagai mediator antara Brand Image terhadap Purchase Intention.

g) $\mathrm{H} 7$ : Terdapat pengaruh Product Involvement terhadap Purchase Intention yang dimediasi oleh Brand Engagement.

Brand Engagement memiliki pengaruh sebagai mediator Product Involvement terhadap Purchase Intention dengan nilai t statistik hitung > t tabel 1,96 (3,047 > 1,96). Dengan kata lain indikator - indikator Brand Engagament yang digunakan dalam penelitian ini berperan sebagai mediator antara Product Involvement terhadap Purchase Intention.

\section{KESIMPULAN}

Berdasarkan pembahasan yang dilakukan maka kesimpulan yang dapat diambil adalah brand image mempengaruhi purchase intention; brand image mempengaruhi brand engagement; product involvement mempengaruhi brand engagement; product involvement mempengaruhi purchase intention; brand engagement mempengaruhi purchase intention; Brand image mempengaruhi purchase intention yang dimediasi oleh brand engagement; Product involvement mempengaruhi purchase intention yang dimediasi oleh brand engagement

\section{DAFTAR PUSTAKA}

Ajisaka. (2012). Teh Khasiatnya Dahsyat. Surabaya: Stomata.

Assael, H. (2001). Consumer Behaviour and Marketing Action (6thed.). Cincinatti: Thompson South-Western Publisher.

Bian, Xuemei., \& Luiz Moutinho. (2011). The Role of Brand Image, Product Involvement, and Knowledge in Explaining Consumer Purchase Behaviour Of Counterfits. European Journal of Marketing. 45(1/2): pp: 191-216

Bowden, J.L.H. 2009. The Process of Customer Engagement: A Conceptual Framework, Journal of Marketing Theory and Practice 17 (1), 63-74

Chien-Hsiung, L. (2011). A Study on The Relations Between The Brand Image and Customer Satisfaction in Catering Businesses. African Journal of Business Management Vol.5 (18), pp. 7732-7739

Damayanthi, E., Kusharto, C. M., Suprihatini, R., \& Rohdiana, D. (2008). Studi Kandungan Katekin dan Turunannya Sebagai Anti Oksidan Alami Serta AKrakateristik Organoleptik Produk Teh Murbei dan Teh Camellia-Murbei. Media Gizi Keluarga, 32 (1), 95-103.

Jaafar, S.N., \& Laalp, Pan, E. (2013). Consumers Perceptions, Attitudes and Purchase Intention Towards Private Label Food Products in Malaysia. Asian Journal of Business and Management Sciences, 2(8), 73-90. 
Jayswal, M. \& Vora, P. (2017). Exploring The Impact Of Brand Engagement On Brand Equity In The Context Of Advergame. International Journal of Management Studies. Vol-IV, Issue I.

Lee, J.L., James, J.D., Kim, Y.K. (2014). A Reconceptualization of Brand Image. International Journal of Business Administration Vol. 5, No. 4; 1-11.

Loureiro, S.M.C., Koo, D., \& Ribeiro, L., (2013). Effects of Atmospherics on Emotions and Intention with Respect to Involvement in Different Shopping Environments. J. Global Sch. Mark. Sci. 23 (4), 435e459.

Madahi, Abdolrazagh., \& Sukati, Inda. (2012). The Effect of External Factors on Purchase Intention Amongst Young Generation in Malaysia. Inter-national Business Research, $5(8), 1-7$

Patterson, C. H. (2004). Do We Need Multicultural Counseling Competencies? Journal of Mental Health Counseling, 26(1),hlm.67-73.

Peter \& Olson. 2013. Perilaku Konsumen dan Strategi Pemasaran. Jakarta: Salemba Empat. 2(9thed).

Quester, P., \& A. L. Lim. (2003). Product Involvement/Brand Loyalty: Is There a Link. Journal of Product \& Brand Management. 12(1): pp: 22-38

Radder.L, \& Huang,W. (2008) "High-Involvement and Low-Involvement Products: A Comparison of Brand Awareness Among Students at A South African University", Journal of Fashion Marketing and Management: An International Journal, Vol. 12 Issue: 2, pp.232-243.

Shah, S., Aziz, J., Jaffari, A. R., Waris, S., Ejaz, W., Fatima, M., et al. (2012). The Impact of Brands on Consumer Purchase Intention. Asian Journal Of Business Management, 4(2), 105-110.

Wang, Yai, H., \& Tsai, Cing, F. (2014). The Relationship Between Brand Image and Purchase Intention: Evidence From Award Winning Mutual Funds. The International Journal of Business and Finance Research, 8(2), 27-40 